\title{
Child Friendly App for Spelling Training
}

\author{
https://doi.org/10.3991/ijoe.v16i04.12315 \\ Ana Sucena Santos ${ }^{\bowtie}$, Ana Filipa Silva, Cristina Garrido, \\ Cátia Marques, Raquel Santos \\ Polytechnic Institute of Porto, Porto, Portugal \\ asucenaless.ipp.pt \\ João Falcão Carneiro, Paulo Abreu, Teresa Restivo \\ University of Porto, Porto, Portugal
}

\begin{abstract}
Spelling skills are usually more difficult to acquire than reading skills. Nonetheless research based intervention proposals are scarce for spelling skills. In this study the impact of a child friendly spelling app on spelling skills is assessed. Results indicate an increase on spelling skills after training with the app.
\end{abstract}

Keywords-Spelling training, spelling difficulties, mobile assisted spelling

\section{Introduction}

Writing difficulties are one of the most frequent complaints among dyslexic adults [1] [2]. Spelling errors potentially affect the readability of the written composition as well as highly contribute for an image of academic incompetence [3] [4]. In fact, for as long as spelling is not automatized, instead consisting on a high cognitive demanding process, the individual is left with few resources for other cognitive processes important for writing such as text production fluency and quality [5] [6] [7].

Reading and spelling acquisition progress interactively. Reading supports spelling through better retention of written words in memory [8] [9]. On the other hand highquality orthographic representations for spelling further support sight word reading [10]. Yet, whereas reading and spelling influence each other, spelling skills are usually more difficult to acquire than reading skills [11]. Children (and adults) who were once poor readers but at some point have compensated their difficulties, usually continue to struggle with spelling [12] [13] [14]. Whereas for reading partial cues or weakly specified orthographic representations may be enough to allow word recognition, spelling requires high-quality orthographic representations [15]. Spelling acquisition consists on the development of the ability to map sounds that are heard in words onto phonologically appropriate letters [16]. This mapping may be more or less straightforward, depending on the phoneme-to-grapheme consistency. If there is a one-to-one consistency, the spelling is unequivocal. If there is one-to-more-than-one mapping the spelling is inconsistent and thus more error prone. Relatively simple Phoneme-Grapheme Correspondences (PGC) are sufficient to decode most words and provide a potent 
self-teaching mechanism to the development of a phonological representation of unfamiliar words [17]. Interventions focusing on phoneme-grapheme mapping are referred to as phonics interventions. A large body of research supports the efficacy of those interventions [18] [19] [20] [21].

Additionally, representing each phoneme with a phonologically plausible letter is not sufficient for skilled spelling. Interventions focusing on training children to deal with deviations from one-to-one mappings between phonemes and graphemes explicitly teach orthographic knowledge. Orthographic knowledge refers to the understanding of the rule system and patterns of written language. Children have to learn the constraints and orthographic rules that govern the positions, combinations and resulting pronunciations of letters within words. Interventions that foster orthographic skills mainly focus on phonological-orthographic regularities, with confirmed efficacy on spelling skills [22].

It is unanimous that spelling acquisition benefits from explicit instruction [23]. Recently, however, some results indicate that explicit instruction may not be sufficient, particularly regarding inconsistent PGC that depend on implicit cues [24]. For the child to develop sensibility to implicit cues an explicit and systematic instruction is crucial. Spelling acquisition should not only include explicit statement of orthographic rules but also massive repetition of similar PGC, in order for the child to become implicitly aware of not only orthographic rules but also most importantly orthographic statistical tendencies.

Educational software has been considered a highly valuable resource for children experiencing spelling and reading acquisition difficulties, as it has the potential to adapt to each individual learning rhythm. Intervention components such as immediate corrective feedback, various exercise opportunities modulated by algorithms that enable the implementation of specialized instructions and adaptive content and motivational aspects such as rewarding system and attractive graphic design are beneficial for spelling skills [25] [26] [27] [28].

Regarding research conducted with Portuguese speaking children, the adaptation of Graphogame for Portuguese and the positive results obtained with at risk first graders has exposed the need of another type of complementary game, with a more interactive nature and with a more pronounced focus on spelling, given the existing comorbidity between reading and spelling problems. Results presented in this article are part of a broader study, focused on the development of the spelling app, for which preliminary results obtained with a different sample have reported a high motivational potential, justified by its interactive nature [29].

Portuguese orthography is considered intermediately shallow. It is mainly consistent on the reading direction but relatively inconsistent on the spelling direction [23] (See Sucena Castro \& Seymour for a thorough description of the Portuguese orthography). In result of this asymmetry Portuguese children become fluent readers before they become accurate spellers (and the more so across dyslexic population). Indeed orthographic errors tend to persist and to be seen as an educational difficulty that should be addressed. Currently there persists the need for (i) more interactive software and (ii) more pronounced focus on spelling [30]. 
In this study, we assessed a prototype of an interactive child-friendly software application focused on spelling, intended to promote sensibility to Portuguese orthographic rules. Specifically, four complex graphemes were trained, within the context of words. Words were presented orally in parallel with the constituent letters that appeared on the screen, shown in a non-sequential order (the grapheme $<\mathrm{nh}>$ corresponding to the phoneme $/ \mathrm{N} /$; the grapheme $<\mathrm{lh}>$ corresponding to the phoneme $/ \mathrm{L} /$; the grapheme $<\mathrm{rr}>$ corresponding to the phoneme $/ \mathrm{R} /$; the grapheme $<$ in $>$ corresponding to the phoneme $/ 3 \mathrm{n} /)_{\text {. }}$

As early intervention has the greatest impact on reading and spelling performance, compared to interventions performed with older children, it was our option to target this app to second graders, as to ensure the intervention occurs early in the spelling development [31] [32].

It is our aim to assess the impact of playing with the app regarding the motivational factor and the orthographic accuracy. Specifically, children were asked to assess the likeability of the app and were assessed (before and after the intervention) regarding the spelling of orthographically complex graphemes within the context of pseudowords. It is our expectation that playing with the app will have a positive impact on the spelling of complex graphemes.

\section{$2 \quad$ Method}

\subsection{Participants}

Participants in this study included 11 second graders, 7 boys and 4 girls, between 6 years and 8 months and 7 years and 8 months, attending schools in the northwest of Portugal. Nine (out of 11) children presented a normal cognitive development and did not show any sensory, motor or cognitive disturbances. Two children presented cognitive deficit (according to school records). All children played with the app.

\subsection{Instruments}

Participants were assessed regarding the spelling of orthographically complex pseudowords. The assessment task consists on spelling four pseudowords dictated by the examiner. Before the four experimental items, one training item is presented. All items include one complex grapheme (the same trained within the app: $<\mathrm{nh}>/ \mathrm{N} / ;<\mathrm{hh}>$ $/ \mathrm{L} ;<\mathrm{rr}>/ \mathrm{R} / ;<\mathrm{in}>/ 3 \mathrm{n} /$ ). The total score corresponds to the total number of pseudowords spelled correctly. At the end of the intervention, after the posttest, participants were asked to rate their degree of satisfaction with the app, adopting a range between 1 (not satisfied) and 5 (totally satisfied).

Regarding the app used in this study, the Piggy Bank is an Android game to be played by children by using both tablets and smartphones and making use of the hardware sensors embedded in those devices (figure 1). 


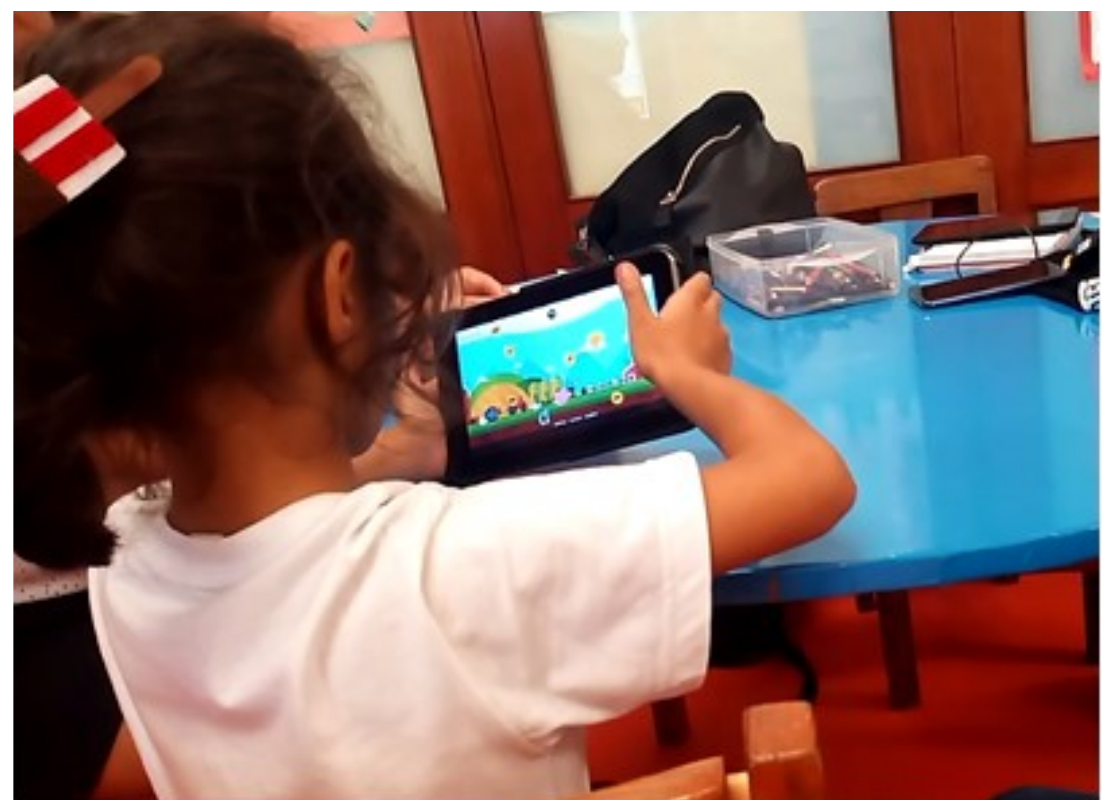

Fig. 1. Child playing the app

The game development took into consideration the four design aspects referred by Schell [32] - aesthetics, story, technology and mechanics. Regarding the aesthetics, the game uses a scenario of a farm with animals, typically from children's entertainments. The story relates to a pig that should be moved by the user in order to collect dropping coins with letters (figure 2).

The technology of the game was kept simple, with the movement of the pig in only one direction (left or right, on the bottom of the user interface) by tilting the device accordingly, using the device embedded accelerometer. The mechanics of the game generates a stimuli from a database within the app, that is presented orally. Simultaneously, coins with random letters that compose the stimuli appear in pseudorandomized order. The child moves the pig to collect them, by the correct order, in order to spell the listened stimuli.

The user starts with 100 points and, for each correct pick of a coin with the correct stimuli, one point is added, and the sound of a dropping coin is played (figure 3 ). An incorrect pick reduces one point the score. The game proceeds (next stimuli is presented) if the answer is correct; the user is required to respell if the answer is incorrect. More details about the app can be consulted in [29]. 


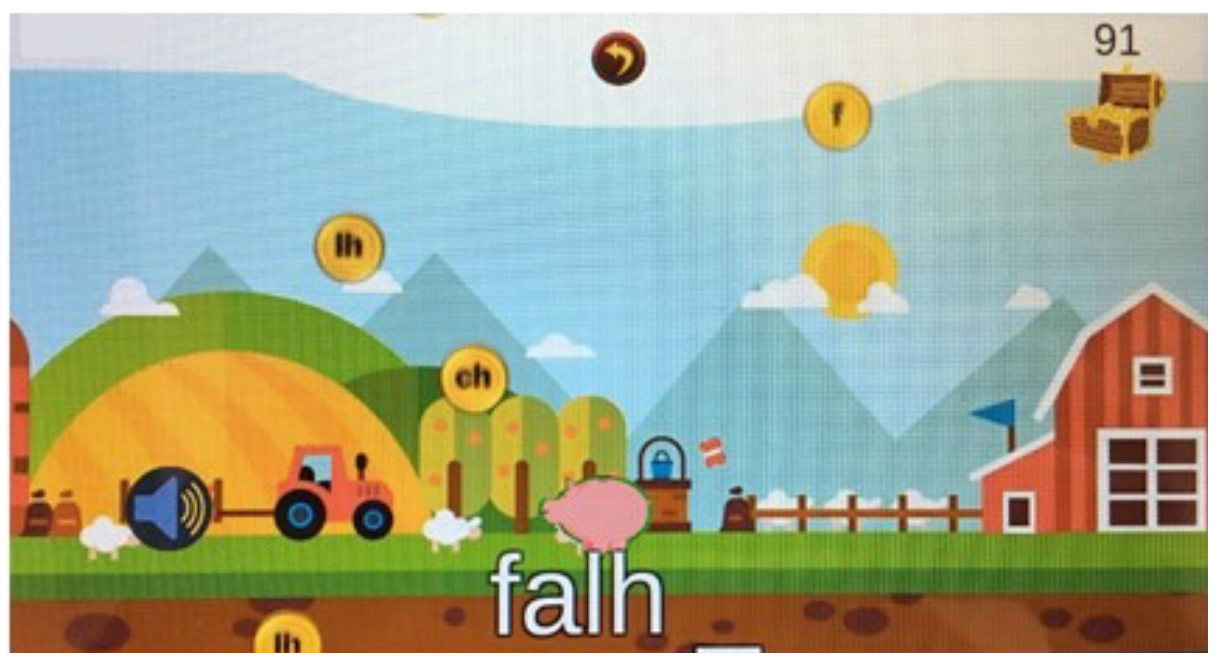

Fig. 2. Game screenshot

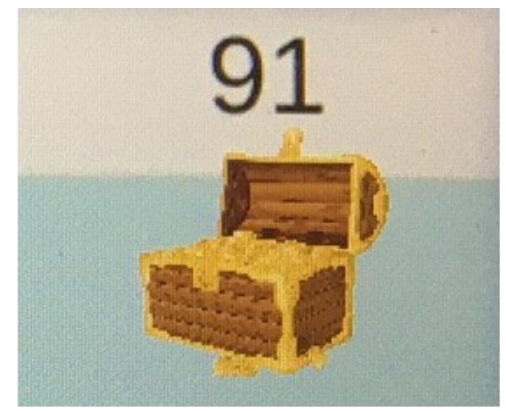

Fig. 3. Game score

\subsection{Procedures of data collection}

Authorizations were obtained from the school board and parents. The objectives of the assessment and training were presented, the confidentiality of the data processing was guaranteed as well as the volunteer participation of all children. Participants were assessed individually in two distinct moments: (i) before training with the app (pretest) and (ii) after training with the app (posttest). Both assessments took place within the school context in a silent and calm environment room. Children played the app around 10 minutes per session, during 5 consecutive days ( 5 sessions). At the beginning of the first session, the app was introduced as a game and the rules were explained. 


\section{Results}

From the 11 children assessed on the pretest, only 7 were also assessed on the posttest. The spelling results of the 7 children in the two assessment moments (pre and posttest) are presented in table 1 .

At the pretest the mean total score was $17 \%$ ( 5 correct spellings out of 28 spellings).

At the posttest the mean total score reached 50\% (14 correct spellings out of 28 spellings). Results varied across the four complex graphemes: at the pretest all participants failed the spelling of $\langle$ nh $>$, only one accurately spelled $<\mathrm{lh}>$ and $<\mathrm{rr}>$, and three accurately spelled $<$ in $>$. There was a positive evolution between assessments, with a rate increase ranging up until $57 \%$.

The number of sessions playing the app ranged between 4 and 5. The number of sessions seems not to impact considerably, on the spelling results, as at the posttest the average spelling results are around 1.3 for those who played during 4 and for those who played during 5 sessions.

Table 1. Results before and after the app use, number of sessions and degree of satisfaction

\begin{tabular}{|c|c|c|c|c|c|c|c|c|c|c|c|c|}
\hline & \multicolumn{5}{|c|}{ Pretest } & \multicolumn{5}{|c|}{ Posttest } & \multirow[b]{2}{*}{$\stackrel{5}{\grave{3}}$} & \multirow[b]{2}{*}{ 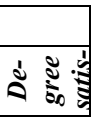 } \\
\hline$\stackrel{\Xi}{\Xi}$ & $\begin{array}{c}<\boldsymbol{< n h} \\
>\end{array}$ & $<\boldsymbol{l h}>$ & $<r r>$ & $<i n>$ & Total & $<\boldsymbol{n h}>$ & $<l h>$ & $<r r>$ & $<i n>$ & Total & & \\
\hline 1 & 0 & 0 & 1 & 0 & 1 & 0 & 1 & 0 & 1 & 2 & 5 & 3 \\
\hline $2^{\mathrm{a}}$ & 0 & 0 & 0 & 0 & 0 & 0 & 0 & 0 & 0 & 0 & 4 & 5 \\
\hline 3 & 0 & 0 & 0 & 1 & 1 & 1 & 0 & 0 & 1 & 2 & 4 & 5 \\
\hline 4 & 0 & 0 & 0 & 0 & 0 & 1 & 1 & 0 & 1 & 3 & 5 & 5 \\
\hline 5 & 0 & 1 & 0 & 1 & 2 & 1 & 1 & 0 & 1 & 3 & 4 & 5 \\
\hline 6 & 0 & 0 & 0 & 1 & 1 & 1 & 1 & 1 & 1 & 4 & 4 & 5 \\
\hline $7^{\mathrm{a}}$ & 0 & 0 & 0 & 0 & 0 & 0 & 0 & 0 & 0 & 0 & 5 & 5 \\
\hline
\end{tabular}

Note: ${ }^{\mathrm{a}}$ cognitive deficit.

\section{Discussion and Conclusion}

In this study, a prototype of a child friendly spelling app was assessed with Portuguese speaking $2^{\text {nd }}$ graders. It was our aim to assess the impact of playing with the app regarding motivation and orthographically complex spelling accuracy.

Educational software is a valuable resource for children experiencing spelling and reading acquisition difficulties. The use of this type of software contributes for intensive but playful training, thus reducing the frequent resistance of children to train skills that they feel are demanding. Throughout the training, children were highly involved thanks to the playfulness of the game - scenario and narrative story of the piggy bank collecting coins - immediate feedback and the reinforcement mechanisms included - money register sound following each accurate selection of letter and system of response cost, by subtracting points for each incorrect letter selection. Most importantly, the game contributed to the spelling acquisition by presenting stimuli with the same complex graphemes, thus promoting the consolidation of the orthographic rules. 
Children assessed the app very positively, in line with previous results [36]. Regarding the impact on spelling accuracy, results indicate a consistent evolution after the training except for those with a cognitive deficit. In fact, this app was developed to average cognitive developing children, identified as at risk of developing difficulties in reading acquisition. The app was not developed for children with cognitive deficits, who apparently do not take any gain from it.

We believe that the development and extension of the app will be useful for average cognitive developing children experiencing spelling difficulties, in parallel with the teacher's pedagogical intervention.

\section{Acknowledgement}

Authors gratefully acknowledge the support of Projects UID/EMS/50022/2019, from Fundação para a Ciência e Tecnologia and NORTE-01-0145-FEDER-000022 SciTech - Science and Technology for Competitive and Sustainable Industries, financed by Programa Operacional Regional do Norte (NORTE2020), within Fundo Europeu de Desenvolvimento Regional (FEDER). This work was also supported by European Horizon 2020, under OPERAÇÃO NORTE-08-5266-FSE-000095.

\section{References}

[1] Holmes, V.M., Castles, A.E. (2001). Unexpectedly poor spelling in university students. Scientific Studies of Reading, 5(4): 319-350 https://doi.org/10.1207/s1532799xssr0504_02

[2] Di Betta, A. M., Romani, M. (2006). Lexical learning and dysgraphia in a group of adults with developmental dyslexia. Cognitive Neuropsychology, 23(3): $376-400$ https://doi.org/10.1080/02643290442000545

[3] Graham, S., Karen, Harris, K., Hebert, M. (2011). It is more than just the message: Presentation effects in scoring writing. Focus on Exceptional Children, 44(4): 1-12 https://doi.org/10.17161/fec.v44i4.6687

[4] Graham, S., Michael Hebert, M. (2011). Writing to read - A meta-analysis of the impact of writing and writing instruction on Reading. Harvard Educational Review, 81(4): 710-744 https://doi.org/10.17763/haer.81.4.t2k0m13756113566

[5] Berninger, V.W. \& Swanson, H.L. (1994). Modifying hayes and flower's model of skilled writing to explain beginning and developing writing. In J.S. Carlson (Series Ed) \& E.C.

[6] Butterfield (Vol Ed), Advances in cognition and educational practice: Volume 2. Children's writing: toward a process theory of the development of skilled writing: 57-81. Greenwich, CT: JAI Press

[7] McCutchen, D. (1996). A capacity theory of writing: Working memory in composition. Educational Psychology Review, 8: 299-324 https://doi.org/10.1007/bf01464076

[8] McCutchen, D. (2000). Knowledge acquisition, processing efficiency, and working memory: Implications for a theory of writing. Educational Psychologist, 35: 13-23 https://doi.org/10.1207/s15326985ep3501 3

[9] Ehri, L.C. (2000). Learning to read and learning to spell: two sides of a coin. Topics in Language Disorders, 20, 3: 19-36 https://doi.org/10.1097/00011363-200020030-00005 
[10] Ehri, L. C. (2014). Orthographic mapping in the acquisition of sight word reading, spelling memory, and vocabulary learning. Scientific Studies of Reading, 18: 5-21 https://doi.org/10.1080/10888438.2013.819356

[11] Ouellette, G., Lyn, S., Chang, M., Rossi, M. (2017). Learning from our mistakes: Improvements in spelling lead to gains in reading speed. Scientific Studies of Reading, 21(4):1-8 https://doi.org/10.1080/10888438.2017.1306064

[12] Bosman, A. M. T., \& Van Orden, G. C. (1997). Why spelling is more difficult than reading. In C. A. Perfetti, L. Rieben, \& M. Fayol (Eds.), Learning to spell: Research, theory, and practice across languages (pp. 173-194). Mahwah, NJ, US: Lawrence Erlbaum Associates Publishers

[13] Afonso, O., Suárez-Coalla, P., Cuetos, F. (2019). Writing impairments in Spanish children with developmental dyslexia. Journal of Learning Disabilities, 0: 1-11 https://doi.org/10.1177/0022219419876255

[14] Maughan, J. Messer, S. Collishaw, A. Pickles, M. Snowling, W. Yule, M. Rutter. (2009). Persistence of literacy problems: spelling in adolescence and at midlife. Journal of Child Psychology and Psychiatry, 50(8): 893-901 https://doi.org/10.1111/j.14697610.2009.02079.x

[15] Moll, K., Landerl, K. (2009). Double dissociation between reading and spelling deficits. Scientific Studies of Reading, 13(5): 359-382 https://doi.org/10.1080/10888430903162878

[16] Perfetti, C., Hart, L. (2002). The lexical quality hypothesis. In C. Verhoeven, C. Elbro, \& P. Reitsma (Eds.), Precursors of functional literacy (pp. 189 -213). Amsterdam, The Netherlands: John Benjamins https://doi.org/10.1075/swll.11.14per

[17] Treiman, R., Decker, K., Kessler, B., Pollo, T. "Variation and repetition in the spelling of young children," Journal of Experimental Child Psychology, vol. 132, pp. 99-110, April 2015 https://doi.org/10.1016/j.jecp.2014.12.008

[18] Rastle, K., Tayler, J. (2006). Print-sound regularities are more important than print-meaning regularities in the initial stages of learning to read: Response to Bowers \& Bowers (2018). Quarterly Journal of Experimental Psychology, 71(7):1-13 https://doi.org/10.117 7/1747021818775053

[19] Ehri, L.C., Nunes, S.R., Stahl, S.A., Willows, D.M. (2001). Systematic phonics instruction helps students learn to read: Evidence from the National Reading Panel's meta-analysis. Review of Educational Research, 71(3): 393-447 https://doi.org/10.3102/00346543071003393

[20] Galuschka, K, Ise, E., Krick, K., Schulte-Körne, G. (2014). Effectiveness of treatment approaches for children and adolescents with reading disabilities: A meta-analysis of randomized controlled trials. Effectiveness of interventions for poor readers, 9(2): 2-12 https://doi.org/10.1371/journal.pone.0089900

[21] McArthur, G., Eve, P. M., Jones, K., Banales, E., Kohnen, S., Anandakumar, T., Castles, A. (2012). Phonics training for English-speaking poor readers. Cochrane Database of Systematic Reviews: 1-103 https://doi.org/10.1002/14651858.cd009115

[22] Weiser, B., Mathes, P. (2011).Using encoding instruction to improve the reading and spelling performances of elementary students at risk for literacy difficulties. Review of Educational Research, 81(2): 170-200 https://doi.org/10.3102/0034654310396719

[23] Squires, K.E., Wolter, J.A. (2016). The effects of orthographic pattern intervention on spelling performance of students with reading disabilities. Remedial and Special Education, 37(6): 357-369 https://doi.org/10.1177/0741932516631115

[24] Sucena, A., Castro, S., Seymour, P. (2009). Developmental dyslexia in an orthography of intermediate depth: The case of European Portuguese. Reading and Writing: An Interdisciplinary Journal, 22: 791-810 https://doi.org/10.1007/s11145-008-9156-4 
[25] Perfetti, C. (1992). "The representation problem in reading acquisition," in Reading acquisition, P. B. Gough, L. C. Ehri, and R. Treiman, Eds. Hillsdale, NJ, US: Lawrence Erlbaum Associates, Inc., 1992, pp. 145-174 https://doi.org/10.4324/9781351236904-6

[26] Wanzek, J., Vaughn, S., Wexler, J., Swanson, E.A., Edmonds, M., Kim, A.H. (2006). A synthesis of spelling and reading interventions and their effects on the spelling outcomes of students with LD. Journal of Learning Disabilities, 39(6):528-43 https://doi.org/10.1177/ 00222194060390060501

[27] Williams, K.J., Walker, M.A., Vaughn, S., \& Wanzek, J. (2017). A synthesis of reading and spelling interventions and their effects on spelling outcomes for students with learning disabilities. Journal of Learning Disabilities, 50(3): 286-297 https://doi.org/10.11 77/0022219415619753

[28] Ecalle, J., Magnan, A., Bouchafa, H., Gombert, J.E. (2009). Computer-based training with ortho-phonological units in dyslexic children: new investigations. Dyslexia, 15(3): 218-238 https://doi.org/10.1002/dys.373

[29] Kast, M., Baschera, G., Gross, M., Jäncke, L., Meyer, M. (2011). Computer-based learning of spelling skills in children with and without dyslexia. Annual of Dyslexia, 1: 1-24 https://doi.org/10.1007/s11881-011-0052-2

[30] Sucena, A., Silva, A. F., Garrido, C., Abreu P., Carneiro J. F., Restivo, M. Teresa. Serious Game for reading and spelling skills, (2019). 5th Experiment International Conference (exp.at'19), Funchal (Madeira Island), Portugal, 2019, pp. 242-243, https://doi.org/10.1 109/expat.2019.8876570

[31] Bree, E., Geelhoed, J., van den Boer, M. (2018). Overruled! Implicit cues rather than an orthographic rule determin Dutch children's vowel spelling. Learning \& Instruction, 56: 3041 https://doi.org/10.1016/j.learninstruc.2018.03.006

[32] Goodwin, A., \& Ahn, S. (2013). A meta-analysis of morphological interventions: Effects on literacy achievement of children with literacy difficulties. Annals of Dyslexia, 60(2):183208 https://doi.org/10.1007/s11881-010-0041-X

[33] Schell, J., The Art of Game Design: A Book of Lens. 2nd Edition ed.: CRC Press

\section{Authors}

Ana Sucena, Ana Filipa Silva, Cristina Garrido, Cátia Marques and Raquel Santos are within Research and Intervention Reading Centre, Polytechnic Institute of Porto (asucena@ess.ipp.pt).

Maria Teresa Restivo, Paulo Abreu and João Falcão Carneiro are within LAETA Research Associate Laboratory of Fundação para a Ciência e Tecnologia and within Faculty of Engineering of University of Porto, Portugal.

Article submitted 2019-11-11. Resubmitted 2020-01-03. Final acceptance 2020-01-04. Final version published as submitted by the authors. 